\title{
Plate forging of drawn cup with flange including thickening of corners
}

\author{
Yohei Abe ${ }^{1, *}$, Ken-ichiro Mori ${ }^{1}$, and Takumi Ito $^{2}$ \\ 1 Department of Mechanical Engineering, Toyohashi University of Technology, 1-1, Tempaku-cho, Toyohashi 441-8580, Japan \\ 2 Graduate Student, Department of Mechanical Engineering, Toyohashi University of Technology, 1-1, Tempaku-cho, \\ Toyohashi 441-8580, Japan
}

Received 23 July 2014 / Accepted 18 September 2014

\begin{abstract}
A plate forging of a drawn cup with a flange including thickening of corners was developed to improve the stiffness of the cup. In a 3-stage stamping process, the bottom and flange corners of the cup with a flange were thickened by the plate forging. A circular blank was drawn with conical punches in the 1st and 2nd stages. In the 3rd stage, the bottom and flange corners were thickened by flattening the conical bottom of the cup with a flange. Both the bottom and flange corners of the cup were thickened by compressing the flange corner in the latter half of the 3rd stage. The amounts of thickening at both corners were improved by modification of intermediate shape. The thickening was concentrated around the two corners by preventing the thickening of the inclined portion. A wheel disk was formed by 6 -stage stamping having the following three stages. The disk had $15 \%$ and $10 \%$ thickening at the bottom and flange corners, respectively, and the bending stiffness of the disk was increased. It was found that the proposed plate forging of sheet metal was considerably effective in increasing in the stiffness and reducing in the weight of automobile parts.
\end{abstract}

Key words: Sheet forming, Plate forging, Thickening, Wheel disk, Corners

\section{Introduction}

The reduction in weight of automobile parts has an effect on the fuel consumption of automobiles. The reduction in weight of wheels directly driven by an engine has particularly an impact on the fuel consumption. Because the requisite strength of the wheels is partially different, the optimized distributions of wall thickness in the wheels leads to the reduction in weight. Thus, it is desirable that the wall thickness in the portion of high strength is thick and that of low strength is thin.

The wheels are classified into those made of steel and aluminium alloy. Although the aluminium alloy wheels produced by casting are attractive for the reduction in the weight, the wheels are expensive [1]. The steel wheels are mostly produced by stamping due to low cost. For the reduction, the application of high strength steel sheets having thin thickness tends to increase in wheel making industry [2]. The mostly produced steel wheels are two-piece structure composed of the disks and rims. The disks and rims are formed by stamping and roll forming operations, respectively [3].

For the reduction in weight of wheel disks, the use of thin high strength sheets such as high-strength steel sheets is

*Corresponding author: abe@plast.me.tut.ac.jp effective. However, the use of thin high strength sheets in the conventional stamping is insufficient for stiffness of the disk because of thinning. The thickness distribution is optimized to have a distribution of required strength and stiffness. Although the strength and the stiffness of the disk are determined by the wall thickness around the bottom corner of the disk, the wall thickness around the bottom corner tends to decrease in the stamping including deep drawing. The decrease in wall thickness around the bottom corner by optimizing drawing ratio in a two-stage forming process of disks has been prevented [4]. Mori et al. [5] have developed a combined forming process of deep drawing and ironing for attaining a thin wall thickness in the outer sidewall of wheel disk.

A sheet-bulk metal forming is developed to fabricate high precision parts with geometric details for automobiles [6]. A plate forging of sheet metals, one of the sheet-bulk metal forming, is used for controlling wall thickness distribution of automobile products [6, 7]. Katoh et al. [8] have proposed a plate forging to increase the side wall thickness of the drawn cup. The flange portion of the step cup is thickened by compression by a multi-motion press machine [9]. The bottom corner of the clutch hub is thickened by plate forging [10]. To increase the wall thickness around the bottom corner of the disk, Tan et al. [11] have proposed a multi-stage stamping including thickening 


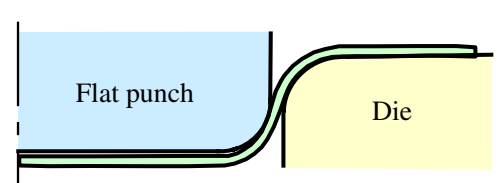

(a)

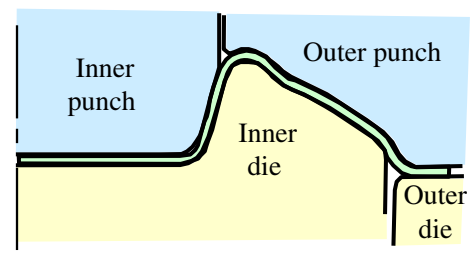

(d)

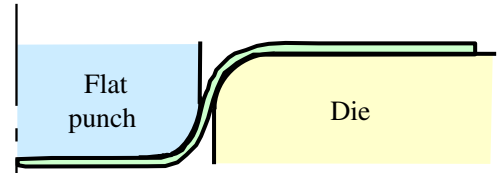

(b)

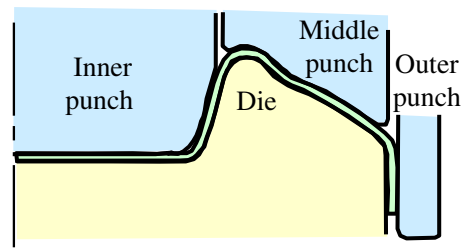

(e)

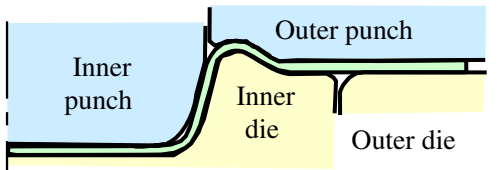

(c)

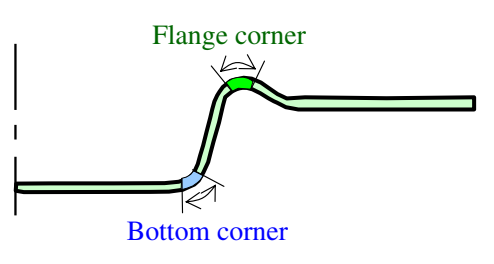

(f)

Figure 1. Stamping process of wheel disk: (a) 1st stage, (b) 2nd stage, (c) 3rd stage, (d) 4th stage, (e) 5th stage and (f) bottom and flange corners in cup with flange formed by three-stage stamping.
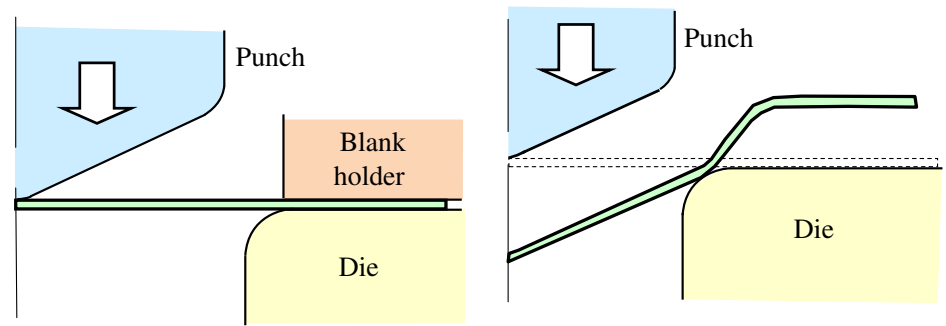

(a)

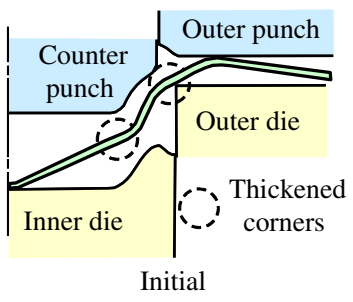

(b)

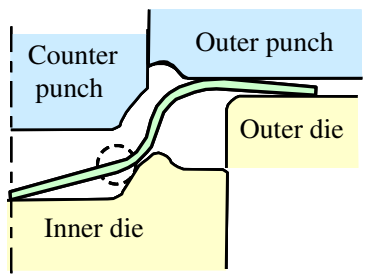

Initial

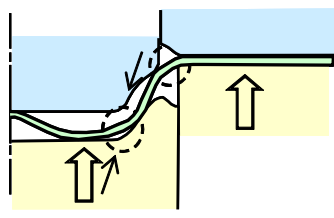

Compression of bottom corner

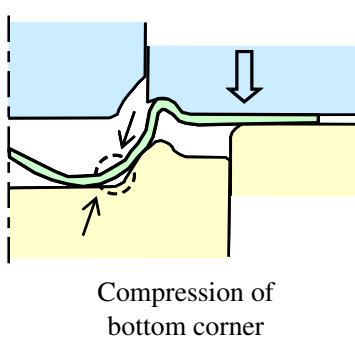

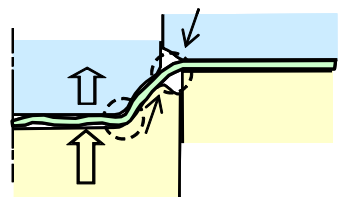

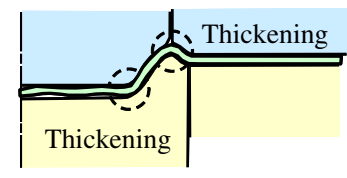

Compression of flange corner

Thickening 2 corners

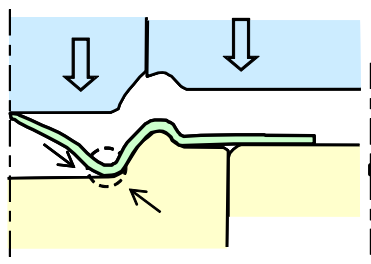

Compression of bottom corner

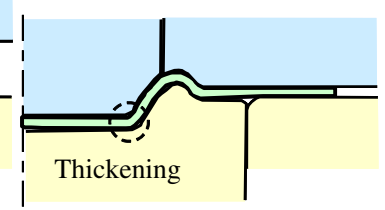

Thickening one corner

(c)

Figure 2. Plate forging of drawn cup with flange: (a) 1st and 2nd stages, (b) thickening of two corners and (c) thickening of one corner.

with conical punches using a blank with uniform thickness. To reduce the weight of the disk, not only the thick bottom corner, but also the thick flange corner is desirable.

Tailor blanks have been widely used to control the thickness distribution and strength of the automobile parts $[12,13]$. In the forming process of a tailor welded blank, the pieces of sheets having different thickness and strength are laser batted-welded. The tailor welded blank [14] and tailor rolled blank [15] have been widely employed in the automobile industry to form the parts having the optimum thickness distribution. Although the wheel disk formed from the axisymmetric tailor welded blank has optimum strength and 


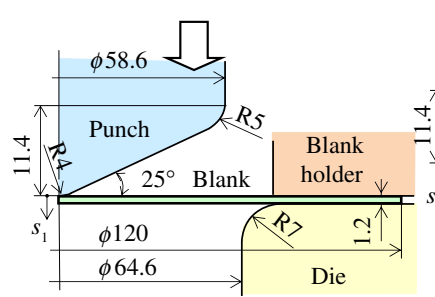

(a)

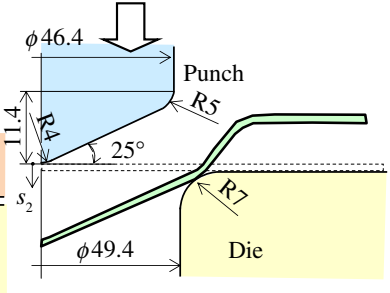

(b)

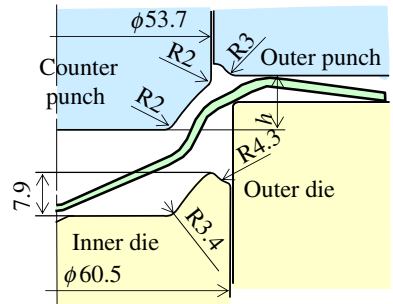

(c)

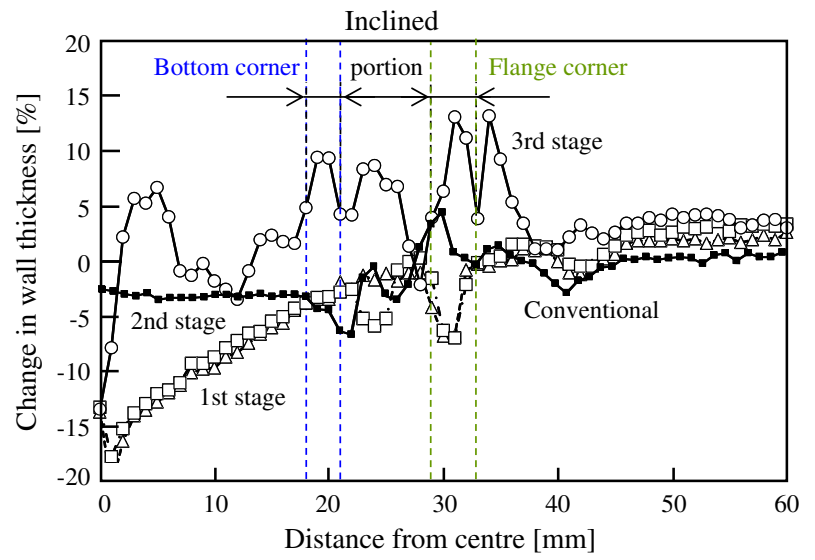

Figure 5. Distribution of change in wall thickness of cup after 3rd stage for $s_{1}=22 \mathrm{~mm}, s_{2}=19 \mathrm{~mm}$ and $h=10 \mathrm{~mm}$.

Figure 3. Stamping conditions in (a) 1st stage, (b) 2nd stage and (c) 3rd stage.

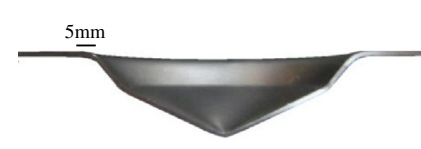

(a)

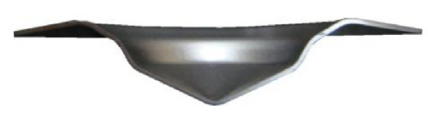

(b)

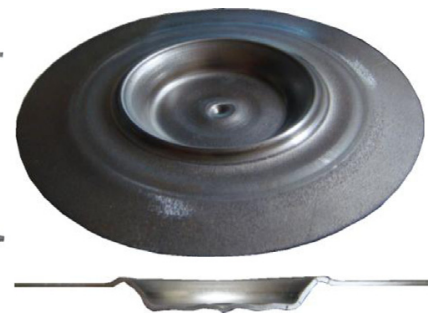

(c)

Figure 4. Cross-sectional shapes of cups for $s_{1}=22 \mathrm{~mm}$, $s_{2}=19 \mathrm{~mm}$ and $h=10 \mathrm{~mm}$ : (a) 1st stage, (b) 2nd stage and (c) 3rd stage.

thickness distributions [16], the welding of three or more pieces of sheet for obtaining the local thickening is not only practical but costly. The use of the tailor rolled blanks is not easy for axi-symmetric parts, however a compression and flexible rolling process was developed to form axi-symmetric tailored blanks [17]. One the other hand, a stamping process of tailor blank having locally thickening was developed $[18,19]$ and then the tailor blanks were applied to increase the wall thickness around the bottom corner in the mild steel [18] and high strength steel disks [20]. The tailor blanks formed by the stamping process were effective in the increase of the wall thickness around the bottom corner. However, the forming cost becomes large due to additional stages for the forming of tailor blanks.

In this study, a plate forging of a drawn cup with a flange including thickening of the bottom and flange corners was proposed. The two corners were thickened by compression of the conical portion of the cup. The amounts of thickening at both corners were improved by control of intermediate shape. The cup with a flange was formed into a miniature wheel disk, and the bending stiffness of the disk was evaluated.

\section{Thickening of bottom and flange corners in multi-stage stamping}

The wheel disk is formed by the multi-stage forming operation as shown in Figure 1 [21]. The required strength and stiffness around the corner of the bottom are high because the bottom flat region of the disk connects to the driven shaft. However, the wall thickness around the bottom corner decreases due to stretching during the deep drawing from 1st to 3rd stages. If the wall thickness around the bottom corner is large enough, the required strength and stiffness around the corner of the flange become high. The wall thickness of the bottom and flange corners is determined by the first three stages. To reduce the weight of the disk, the multi-stage stamping including thickening of the bottom and flange corners using plate forging is desirable.

The plate forging of the cup with flange for thickening of two corners is illustrated. In Figure $2 \mathrm{a}$, the cups with flange having conical bottom are drawn in the deep drawing in the 1 st stage and the redrawing in the 2 nd stage. In the thickening of two corners in Figure 2b, the wall thickness around the bottom corner is increased by compressing in the early stage. The wall thickness around the flange corner is increased by compressing the flange corner in the latter half of the stage. In the thickening of one corner, the wall thickness around the bottom corner is only increased as shown in Figure 2c.

Only the first three-stage forming process in Figure 1 is dealt with in this chapter because the wall thickness around the bottom and flange corners hardly changes in the 4th and 5 th stages. The stamping conditions in three-stage are shown in Figure 3. The three-stage forming process of mild steel (SPCC) blanks was performed, where the size of the model is $1 / 3.5$ of the actual wheel disk. The thickness and diameter of the blank are $1.2 \mathrm{~mm}$ and $120 \mathrm{~mm}$, respectively. The tensile strength, elongation and $n$-value of the SPCC sheet measured by uni-axial tension test are $342 \mathrm{MPa}, 43 \%$ and 0.22 . The conical punches having a conical bottom are used in the deep drawing in the 1st stage and the redrawing in the 2nd stage. 


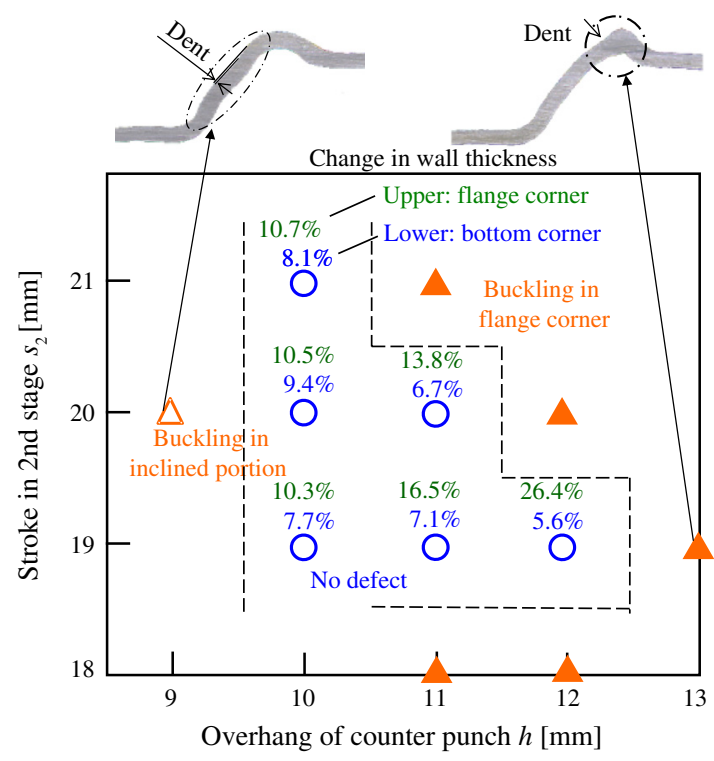

(a)

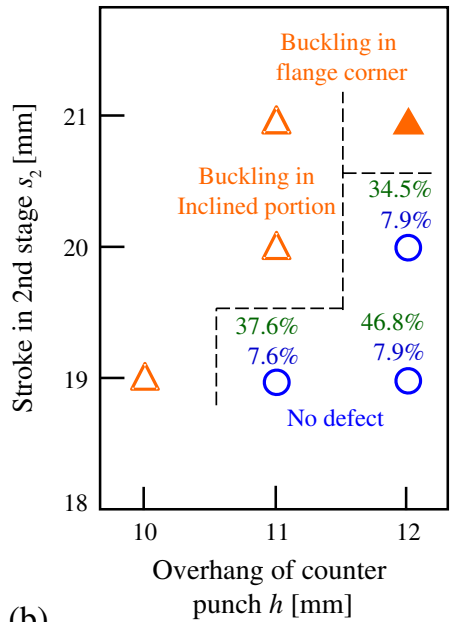

(b)

Figure 6. Forming range and changes in wall thickness at flange and bottom corners: (a) $s_{1}=23 \mathrm{~mm}$ and (b) $s_{1}=24 \mathrm{~mm}$.
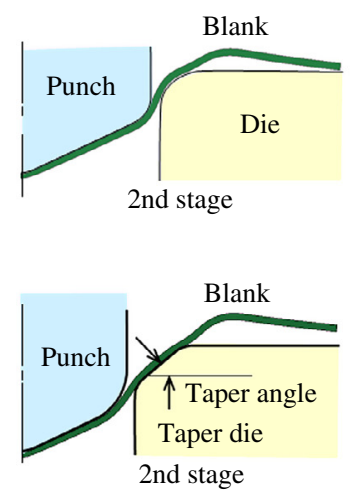

Counter punch

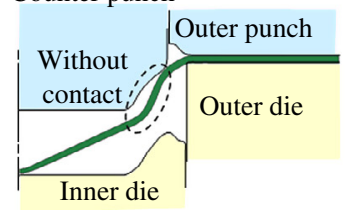

(a) Without contact

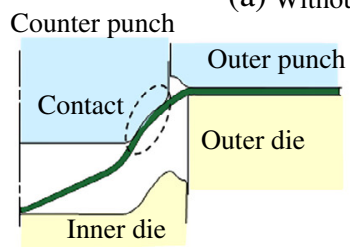

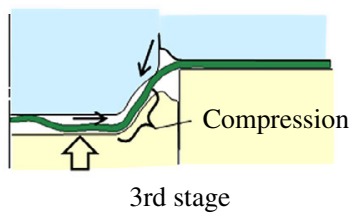

3rd stage

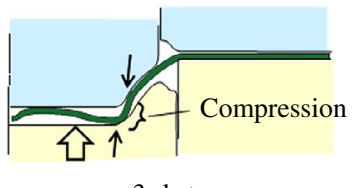

3rd stage
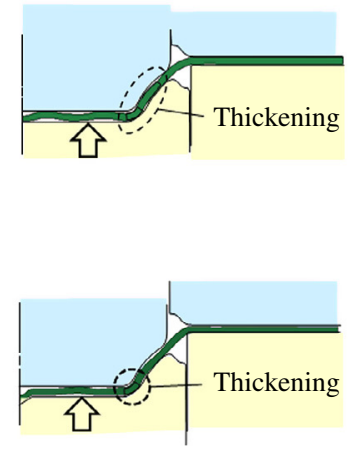

(b) With contact

Figure 7. Improvement of thickening of two corners by contact of inclined portion between two corners: (a) without contact and (b) with contact in thickening of 3rd stage.

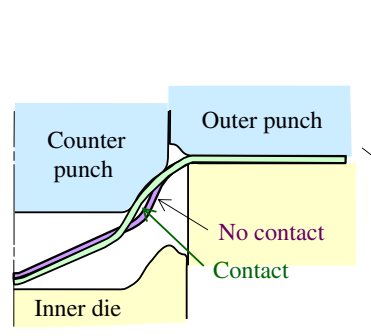

(a)

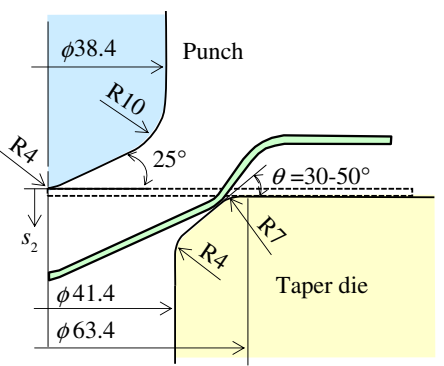

(b)

Figure 8. Forming conditions in (a) 3rd stage and (b) 2nd stage to improve thickening of two corners.

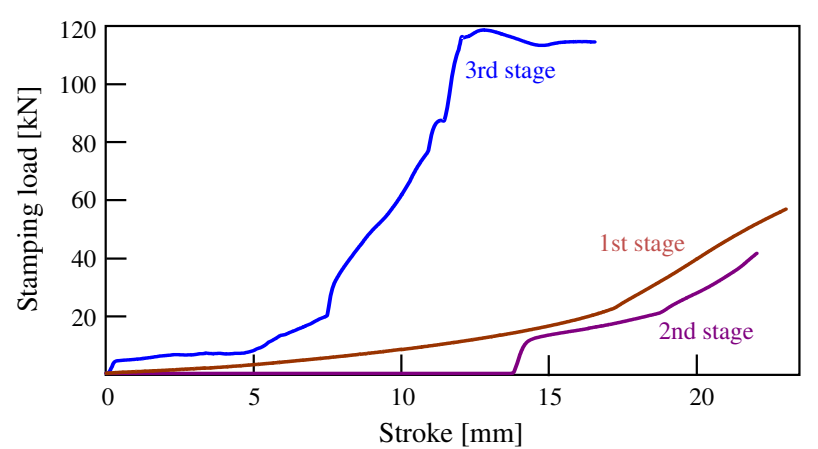

Figure 9. Stamping load-stroke curve for $\theta=45^{\circ}$ and $s_{2}=22 \mathrm{~mm}$. 


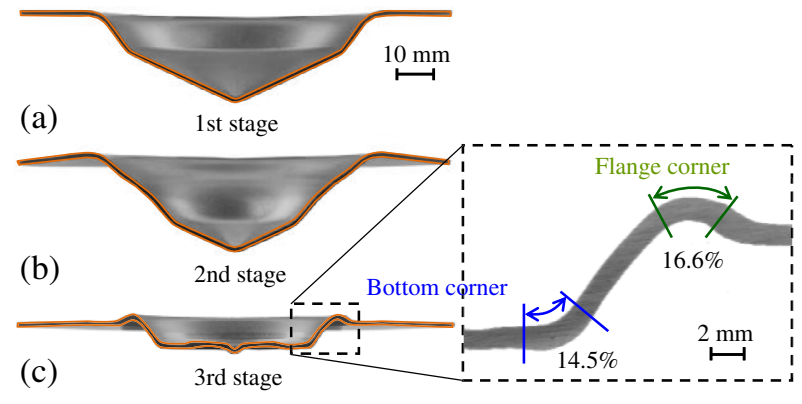

Figure 10. Cross-sections of cups for $\theta=40^{\circ}$ and $s_{2}=20 \mathrm{~mm}$.

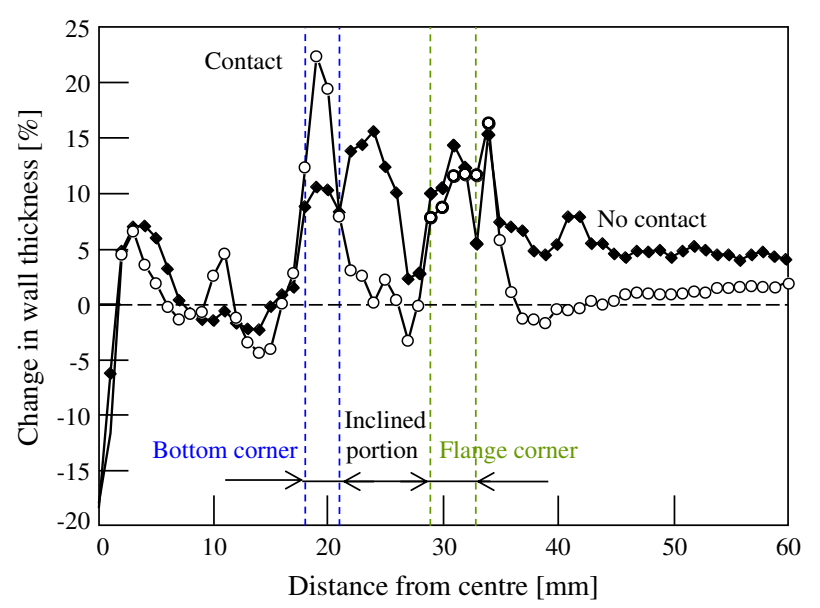

Figure 11. Distribution of change in wall thickness of cup after 3rd stage for $\theta=45^{\circ}$ and $s_{2}=22 \mathrm{~mm}$.

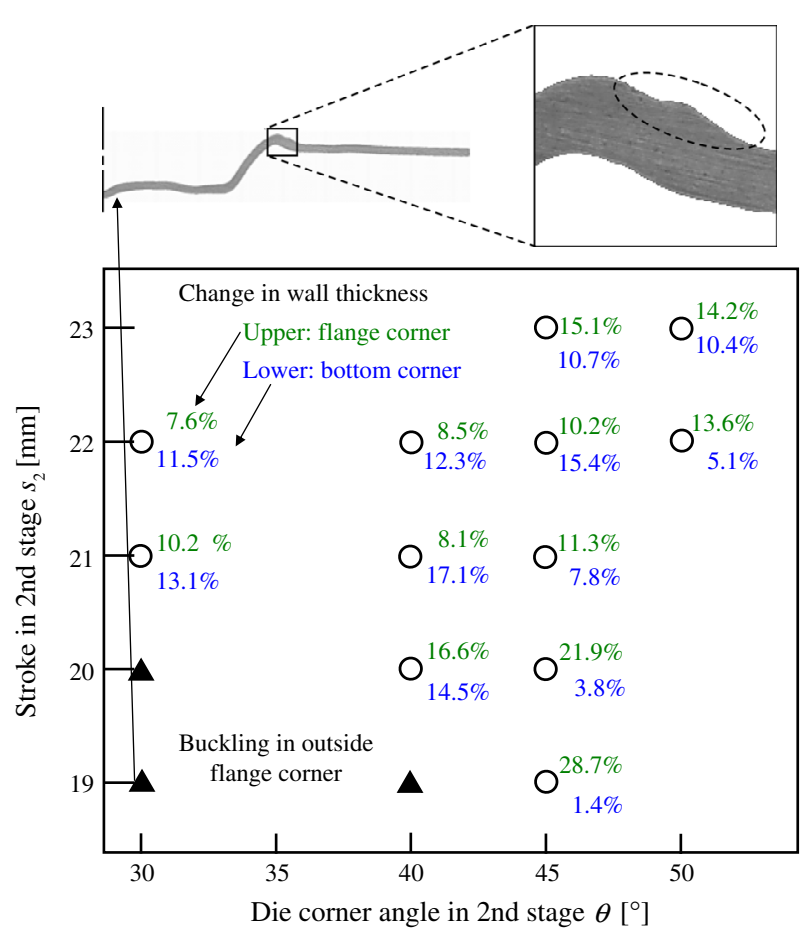

Figure 12. Forming range and changes in wall thickness at flange and bottom corners for contact of inclined portion with counter punch in 3rd stage.
In the 3rd stage, the conical bottom of the cup is compressed to increase the corners. The volume and intermediate shape of the drawn cup are controlled by punch strokes $s_{1}$ and $s_{2}$ in the 1st and 2nd stages. The overhang of counter punch $h$ is changed to control the deforming behavior in the 3rd stage.

The cross-sectional shapes of cups for $s_{1}=22 \mathrm{~mm}$, $s_{2}=19 \mathrm{~mm}$ and $h=10 \mathrm{~mm}$ are shown in Figure 4 . The conical bottom of the cup is formed with the conical punches in the 1 st and 2 nd stages. In the 3rd stage, the conical bottom of the cup is compressed, and then the cup with the flange is formed. The deformation is axi-symmetric.

The distribution of change in wall thickness of cup after $3 \mathrm{rd}$ stage for $s_{1}=22 \mathrm{~mm}, s_{2}=19 \mathrm{~mm}$ and $h=10 \mathrm{~mm}$ is shown in Figure 5. Maximum 10\% and 13\% of increments in thickness around the bottom and flange corners are obtained. Because the central portion of the cup is punched as a hub hole of the wheel, this thinning is not a defect. In the conventional process, the thinning around the bottom corner appears.

The forming range is shown in Figure 6. The average changes in the wall thickness at flange and bottom corners are shown in the figure. The buckling in the flange corner appears in the large overhang of counter punch. The buckling in the inclined portion appears in the small overhang of counter punch. In the large stroke in 1st stage, the buckling tends to occur due to excessive volume of the drawn cup. The dent caused by buckling is a surface defect. Although the corners are thickened by the proposed process, the increment in the bottom corner is smaller. In this chapter, a combination of $s_{1}=23 \mathrm{~mm}, s_{2}=20 \mathrm{~mm}$ and $h=10 \mathrm{~mm}$ is suitable for the disk having optimum thickness distribution.

\section{Improvement of thickening of two corners by control of intermediate shape}

The thickening of bottom corner was improved by control of intermediate shape. The improvement of thickening of two corners by contact of the inclined portion between the two corners with the counter punch in the 3rd stage is shown in Figure 7. In the contact of the inclined portion without the counter punch, not only the bottom corner, but also the inclined portion between the corners are compressed, thus the increment of the thickness at the bottom corner reduces. In the contact with the counter punch, the compression is concentrated in the bottom corner and then the increment of the thickness is accelerated.

The conditions in the 3rd and 2nd stages are shown in Figure 8. To contact the inclined portion with the counter punch in the 3rd stage, the geometries of tools were modified. The intermediate shape was controlled by punch stroke $s_{2}$ and the taper angle $\theta$ in the 2 nd stage. In this chapter, the overhang of counter punch was set to contact with the blank.

The stamping load-stroke curve for $\theta=45^{\circ}$ and $s_{2}=22 \mathrm{~mm}$ is shown in Figure 9. The stamping loads in the 1 st and 2nd stages are not large because of deep drawing. The load in the 3rd stage is larger due to the compression of the corners.

The cross-sections of the cup for $\theta=40^{\circ}, s_{2}=20 \mathrm{~mm}$ are illustrated in Figure 10. In the 1st and 2nd stages, the cups having the conical bottom with the flange were formed by the deep 

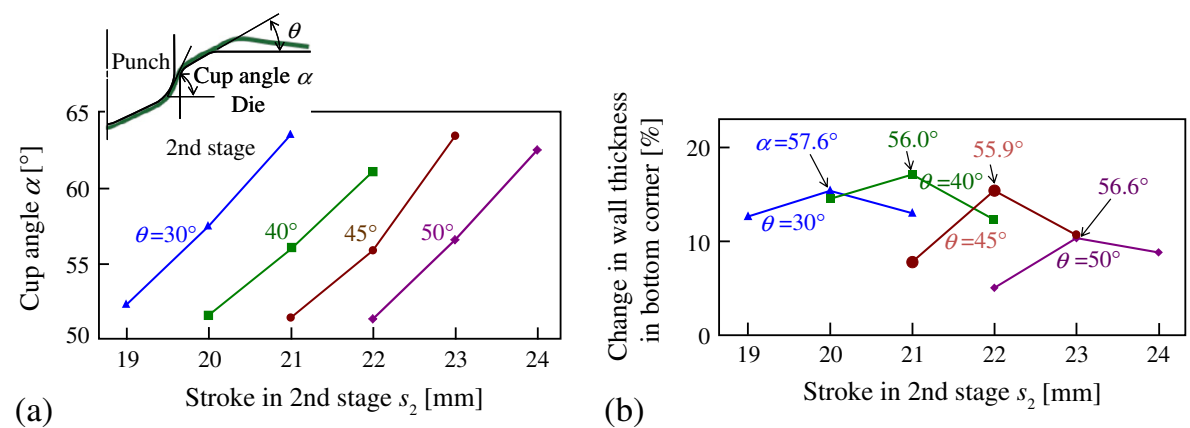

Figure 13. Effect of conditions in 2nd stage on change in wall thickness in bottom corner. (a) Cup angle after 2nd stage and (b) effect of cup angle after 2 nd stage on change in wall thickness in bottom corner.

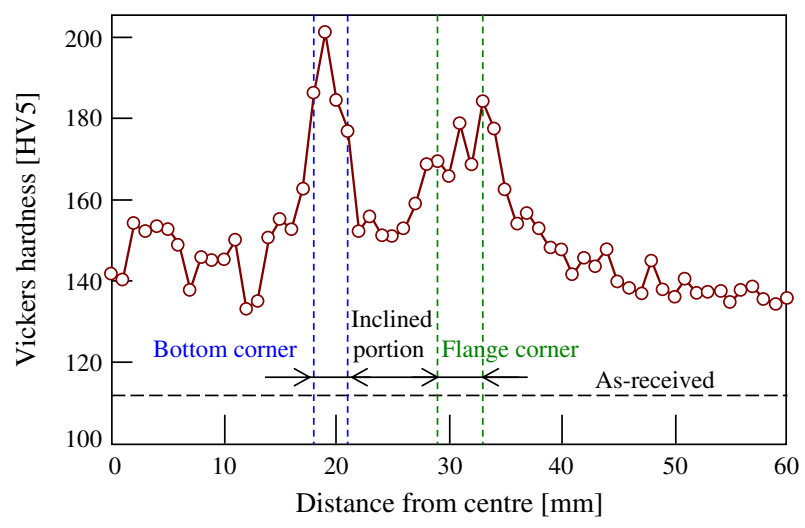

Figure 14. Distribution of Vickers hardness of cup after 3rd stage for $\theta=45^{\circ}$ and $s_{2}=22 \mathrm{~mm}$.

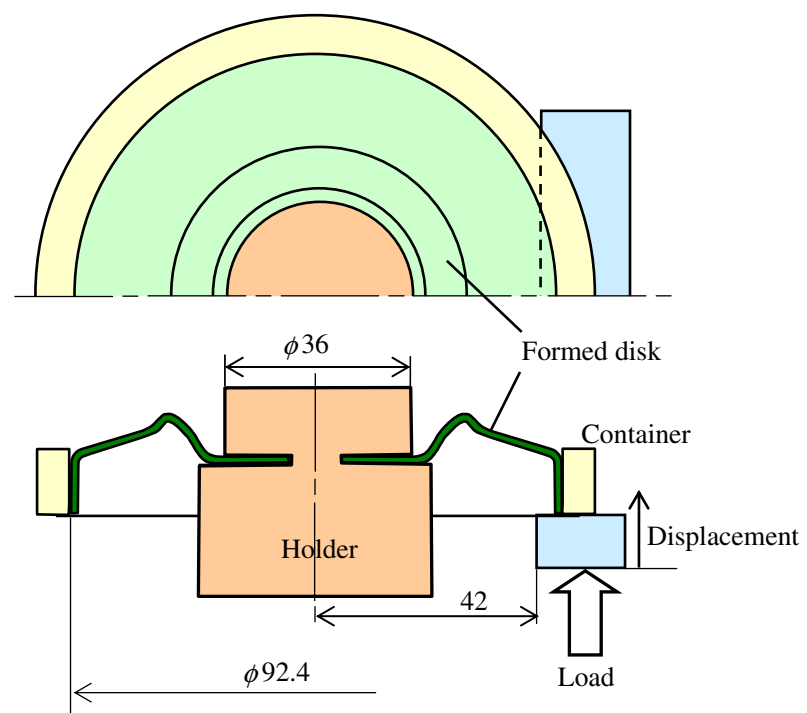

Figure 15. Measurement of bending stiffness of wheel disk formed by six-stage stamping.

drawing. After the 3rd stage, the drawn cup having thickened corners is formed.

The distribution of the change in the wall thickness of the cup after the $3 \mathrm{rd}$ stage for $\theta=45^{\circ}$ and $s_{2}=22 \mathrm{~mm}$ is shown in

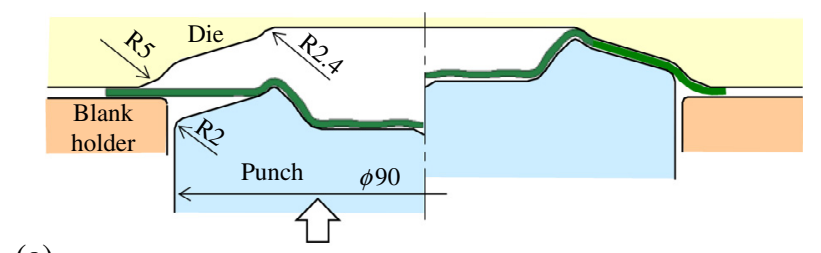

(a)

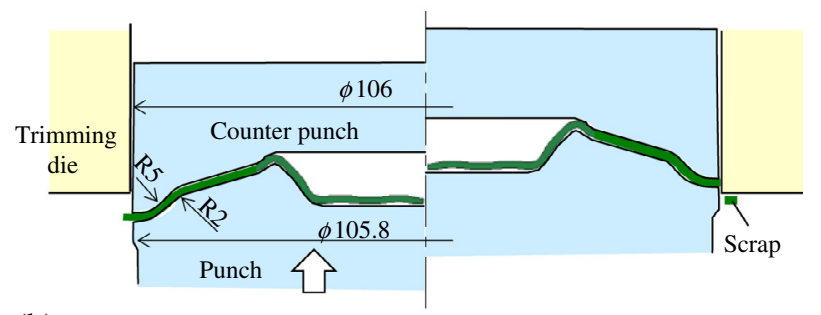

(b)

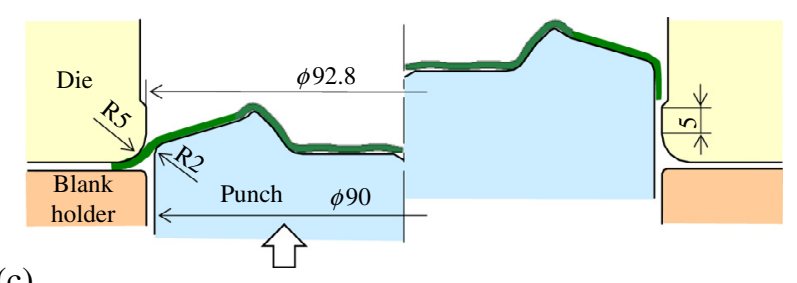

Figure 16. Conditions for forming of wheel disk: (a) 4th stage, (b) 5th stage and (c) 6th stage.

Figure 11. In the no-contact, $s_{1}=22 \mathrm{~mm}, s_{2}=19 \mathrm{~mm}$ and $h=10 \mathrm{~mm}$ were used. The maximum change in wall thickness is about $10 \%$ in the bottom corner without contact. However, the maximum change with contact is about $22 \%$ due to the concentrate of compression.

The forming range and the changes in the wall thickness at the flange and bottom corners for contact of the inclined portion with the counter punch in the 3rd stage are shown in Figure 12. In the range of the small stroke and the small die corner angle in the 2nd stage, the buckling in outside flange corner appears due to much material in the flange corner. The wall thickness in both corners is controlled by the intermediate shape. In this study, the condition of $\theta=45^{\circ}$ and $s_{2}=22 \mathrm{~mm}$ was selected. 


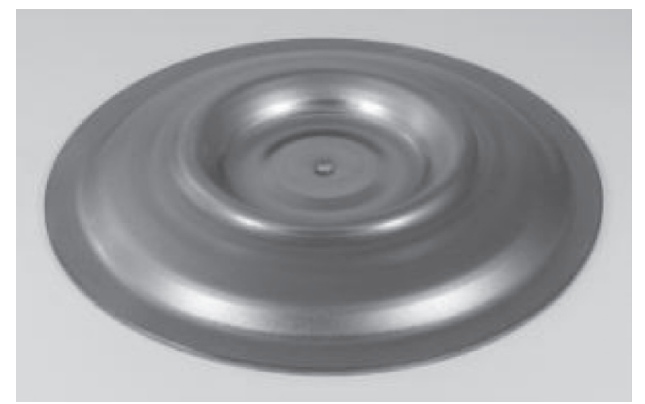

(a)
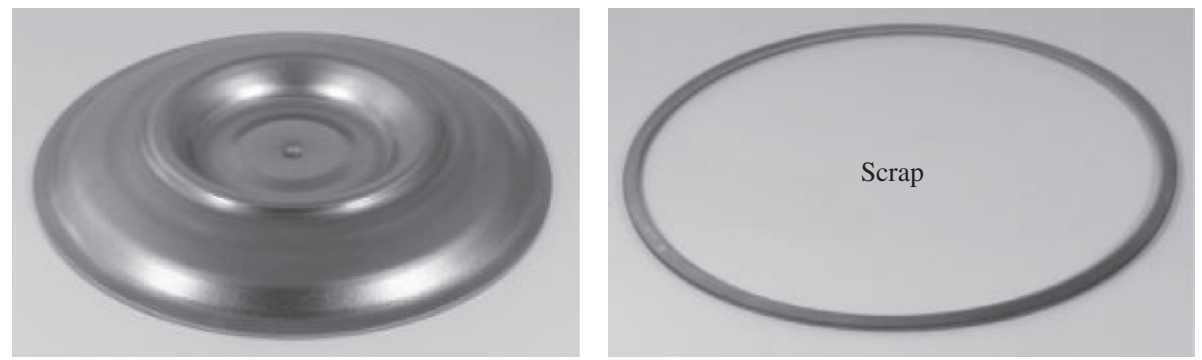

(b)

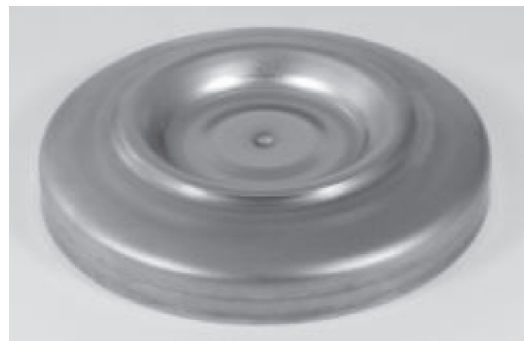

(c)

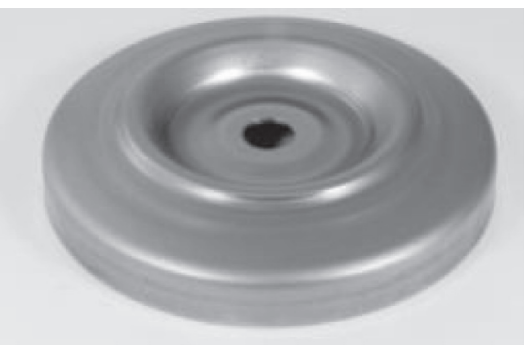

(d)

Figure 17. (a) 4th stage, (b) 5th stage, (c) 6th stage and (d) drilled disk.

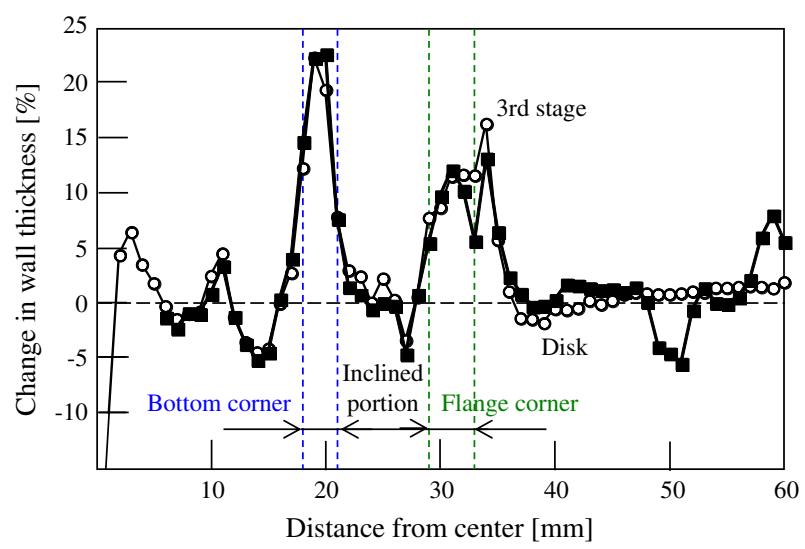

Figure 18. Distribution of change in wall thickness of formed disk.

The effect of conditions in the 2nd stage on the change in the wall thickness in the bottom corner is shown in Figure 13. The cup angle increases with the stroke and die corner angle in the 2nd stage shown in Figure 13a. The optimum stroke in the 2nd stage in each die corner angle is shown. Thus about $56^{\circ}$ of

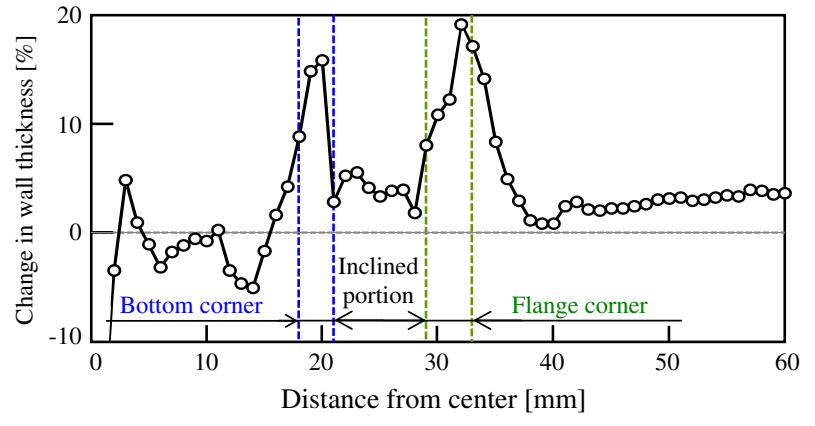

Figure 19. Distribution of change in wall thickness of disk with $590 \mathrm{MPa}$ steel blank having $1 \mathrm{~mm}$ of thickness.

the cup angle is suitable to increase the wall thickening in Figure 13b.

The distribution of Vickers hardness of the cup after the 3rd stage for $\theta=45^{\circ}$ and $s_{2}=22 \mathrm{~mm}$ is shown in Figure 14 . The hardness of the cup is increased by the plastic deformation. Both corners are especially large because of large plastic deformation. 

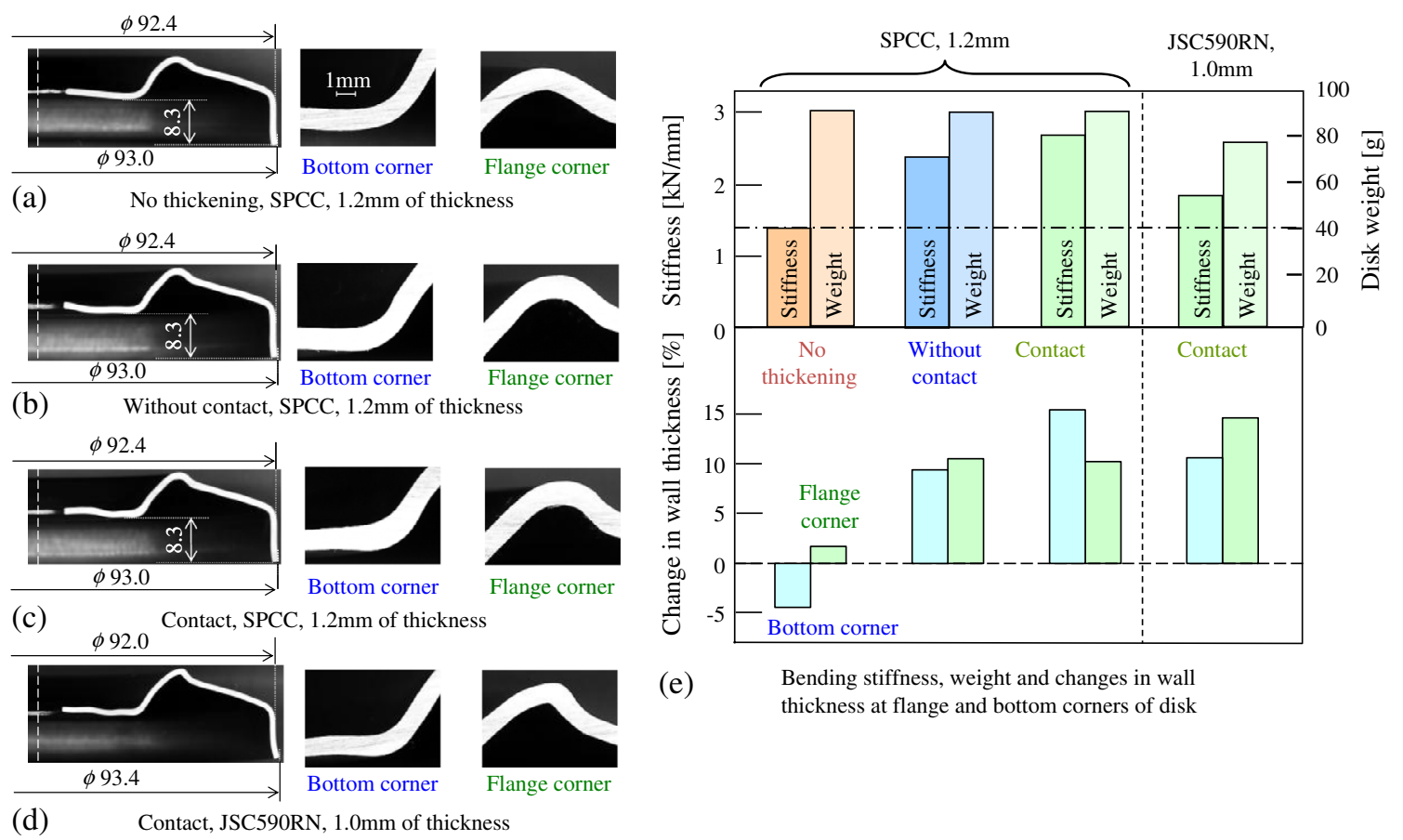

Figure 20. Cross-sections, bending stiffness, weight and changes in wall thickness at flange and bottom corners of disk.

\section{Bending stiffness of forming wheel disk and light weight disk using high strength steel sheet}

The bending stiffness of the formed wheel disk was measured. The formed cup with flange was formed into wheel disk with a following three-stages. The load was applied to a side of wheel disk shown in Figure 15, and then the load and displacement were measured in the elastic deformation of the disk. The bending stiffness is the ratio of the load and displacement.

The following three stages to form into wheel disk are shown in Figure 16. In the 4th stage, the outer taper portion of the cup is drawn. The edge of the flange is trimmed in the 5 th stage. The 5th stage is added in this study to form disks having same height, not required in the actual production. The flange portion is drawn in the 6th stage.

The formed parts are shown in Figure 17. The cup for $\theta=45^{\circ}$ and $s_{2}=22 \mathrm{~mm}$ was used. The wheel disk is formed without defect. The central portion of wheel disk is drilled to fix in the measuring of the bending stiffness in Figure 15d.

The distribution of the change in the wall thickness of formed disk is shown in Figure 18. The distribution from the centre to the flange corner in the disk is similar to that of the formed cup after 3 rd stage. The wall thickness in the flange portion of the disk is slightly reduced by the following 3-stage.

A $590 \mathrm{MPa}$ steel (JSC590RN) blank having $1 \mathrm{~mm}$ of thickness was formed into disk to compare with mild steel sheet. The tensile strength, elongation and $n$-value of the JSC590RN sheet measured by uni-axial tension test are $603 \mathrm{MPa}, 27 \%$ and 0.17 . The distribution of the change in the wall thickness of the formed disk from $590 \mathrm{MPa}$ steel blank for $\theta=45^{\circ}$ and $s_{2}=22 \mathrm{~mm}$ is shown in Figure 19 . The bottom and flange corners are thickened.
The cross-sections, the bending stiffness, the weight and changes in wall thickness at flange and bottom corners of the disk are shown in Figure 20. The bending stiffness of the mild steel disk with the contact is the highest due to the thick wall thickness in the corners. The wheel disk formed by 6-stage stamping having the following three stages has $15 \%$ and $10 \%$ thickening at the bottom and flange corners, respectively, and the bending stiffness is 1.7 times as large as that without thickening. The stiffness of the $590 \mathrm{MPa}$ steel disk is larger than that of no thickening. The weight of JSC590RN disk is about $14 \%$ lighter than that of SPCC one without thickening, thus it is effective to reduce the weight of the disk using the thin $590 \mathrm{MPa}$ steel sheet.

\section{Conclusions}

Because the requisite stiffness and strength of the automobile parts are partially different, the optimized distributions of wall thickness in the parts lead to the reduction in weight having sufficient stiffness. In this study, a plate forging of a drawn cup with a flange was proposed to thicken the bottom and flange corners for reduction in weight of wheel disk. Two corners were thickened by compression of the inclined portion of the cup in the 3rd stage, then amounts of thickening at both corners were improved by control of intermediate shape. The cup with a flange was formed into a miniature wheel disk. A wheel disk formed by 6-stage stamping having the following three stages had $15 \%$ and $10 \%$ thickening at the bottom and flange corners, respectively, and the bending stiffness was 1.7 times as large as that without thickening. The proposed process was applied to a thinner $590 \mathrm{MPa}$ steel blank. The stiffness of the $590 \mathrm{MPa}$ steel disk was larger than that of mild steel one with no thickening. It is found that the proposed plate forging 
is considerably effective in increasing in the stiffness and reducing in the weight of disks, therefore, the plate forging including control of the thickness distribution in the sheet forming is an important technology for the production of lightweight automobile parts.

\section{References}

1. D. Fauth, Society of Automotive Engineers, Publication no. 800-231 (1980) 5 .

2. Fitz F., Gadd C., Spec. Publ. Soc. Automot. Eng. SP-1439, 13 (1999).

3. Hibon G., Marron G., Patou P., Proc. of the 19th IDDRG, 33 (1996).

4. Y. Abe, K. Mori, O. Ebihara, J. Mater. Process. Technol. 125-126 (2002) 792.

5. K. Mori, O. Ebihara, K. Yoshii, Y. Abe, Intelligence in a Mater. World J.A. Meech (ed.) (2003) 305.

6. M. Merklein, J.M. Allwood, B.-A. Behrens, A. Brosius, H. Hagenah, K. Kuzman, K. Mori, A.E. Tekkaya, A. Weckenmann, CIRP Ann. - Manuf. Technol. 61-2 (2012) 725.

7. K. Mori, Proc. 14th International Conference on Metal Forming, Krakow, 17 (2012)

8. K. Katoh, K. Kondo, K. Satoh, Proceedings of the 7th International Conference on Technology for Plasticity 2 (2002) 103
9. T. Suzumura, K. Mine, I. Hirayama, S. Ishihara, Proceedings of the 7th International Conference on Technology for Plasticity 2 (2002) 1093

10. H.-C. Wu, T. Altan, J. Mater. Process. Technol. 146 (2004) 8

11. C.J. Tan, Y. Abe, K. Mori, O. Ebihara, T. Nonaka, Key Eng. Mater. 340-341 (2007) 761.

12. R.J. Pallett, R.J. Lark, J. Mater. Process. Technol. 117-122 (2001) 249.

13. M. Merklein, M. Johannes, M. Lechner, A. Kuppert, J. Mater. Process. Technol. 214 (2014) 151.

14. H. Kusuda, T. Takasago, F. Natsumi, J. Mater. Process. Technol. 71-1 (1997) 134.

15. M. Urban, M. Krahn, G. Hirt, R. Kopp, J. Mater. Process. Technol. 177 (2006) 360.

16. G. Marron, P. Verrier, Society of Automotive Engineers Spec. Publ. SP-1439 (1999) 23.

17. S. Opel, T. Schneider, M. Merklein, Key Eng. Mater. 554-557 (2013) 1459.

18. C.J. Tan, K. Mori, Y. Abe, J. Mater. Process. Technol. 202-1-3 (2008) 443.

19. M. Merklein, S. Opel, AIP Conf. Proc. 1315 (2011) 395.

20. C.J. Tan, K. Mori, Y. Abe, M. Suzuki, Steel Res. Int. 81-9 (2010) 833, Supplement Metal Forming 2010.

21. I. Machida, M. Narita, R. Kureura, H. Morishita, Y. Yoshimura, K. Itakura, Honda R \& D Technical Review 6 (1994) 146.

Cite this article as: Abe Y, Mori K-I \& Ito T: Plate forging of drawn cup with flange including thickening of corners. Manufacturing Rev. $2014,1,16$. 